\title{
Long term and short term oral anticoagulation treatments were equivalent for venous thromboembolism
}

\author{
Pinede L, Ninet J, Duhaut P, et al, for the Investigators of the "Durée Optimale du Traitement AntiVitamines K" (DOTAVK) \\ Study. Comparison of 3 and 6 months of oral anticoagulant therapy after a first episode of proximal deep vein thrombosis \\ or pulmonary embolism and comparison of 6 and 12 weeks of therapy after isolated calf deep vein thrombosis. \\ Circulation 2001 May 22;103:2453-60.
}

\section{QUESTION: In patients with proximal deep venous thrombosis (PDVT) or pulmonary embolism, or both, or isolated calf deep venous thrombosis (CDVT), is long term treatment better than short term treatment with oral anticoagulants for preventing recurrences and bleeding complications?}

Sources of funding:

French Ministry of Health; Hospices Civils de Lyon; Conseil

Régional Rhône-Alpes;

Association pour la

recherché et l'évaluation

thérapeutique

(APRET).

For correspondence: $\mathrm{Dr}$ $L$ Pinede, Department of Internal Medicine, Edouard Herriot Hospital, 69437 Lyons Cedex 03, France. Fax +334721 17567.

\section{Design}

Randomised (allocation concealed*), unblinded,* controlled trial with 15 months of follow up.

Setting

France.

\section{Patients}

736 patients (mean age 59 y, 53\% women) who had symptomatic PDVT or pulmonary embolism, or both, or symptomatic CDVT confirmed by objective diagnostic tests. Exclusion criteria included pregnancy, breast feeding, vena cava filter implantation, surgical thrombectomy, free-floating thrombus in the inferior vena cava,

Long term $v$ short term treatment with oral anticoagulants for venous thromboembolism ${ }^{\dagger}$

\begin{tabular}{|c|c|c|c|c|}
\hline Outcomes at $15 \mathrm{mo}$ & $\begin{array}{l}\text { Long } \\
\text { term } \\
\text { (12 wk) }\end{array}$ & $\begin{array}{l}\text { Short } \\
\text { term } \\
(6 \mathrm{wk})\end{array}$ & RRI $(95 \%$ Cl) & NNH \\
\hline \multicolumn{5}{|l|}{ CDVT } \\
\hline Recurrence & $3 \%$ & $2 \%$ & $71 \%(-65$ to 743$)$ & Not significant \\
\hline $\begin{array}{l}\text { Haemorrhage (major, } \\
\text { minor, or fatal) }\end{array}$ & $21 \%$ & $12 \%$ & $66 \%(-12$ to 216$)$ & Not significant \\
\hline \multirow[t]{2}{*}{ Major haemorrhage } & $3 \%$ & $1 \%$ & $242 \%(-50$ to 2269$)$ & Not significant \\
\hline & $\begin{array}{l}\text { Long } \\
\text { term } \\
(6 \mathrm{mo})\end{array}$ & $\begin{array}{l}\text { Short } \\
\text { term } \\
(3 \mathrm{mo})\end{array}$ & & \\
\hline \multicolumn{5}{|l|}{ PDVT/PE } \\
\hline Recurrence & $9 \%$ & $8 \%$ & $10 \%(-37$ to 92$)$ & Not significant \\
\hline \multirow[t]{2}{*}{$\begin{array}{l}\text { Haemorrhage (major, } \\
\text { minor, or fatal) }\end{array}$} & $17 \%$ & $16 \%$ & $7 \%(-26$ to 57$)$ & Not significant \\
\hline & & & $\operatorname{RRR}(\mathrm{Cl})$ & NNT \\
\hline Major haemorrhage & $2 \%$ & $3 \%$ & $60 \%(-45$ to 363$)$ & Not significant \\
\hline
\end{tabular}

†CDVT = calf deep venous thrombosis; PDVT/PE = proximal deep venous thrombosis or pulmonary embolism, or both. Other abbreviations defined in glossary; RRI, RRR, NNH, NNT, and Cl calculated from data in article. active cancer or malignant haematological disease, or a previous venous thromboembolism. $97 \%$ of patients completed the study.

\section{Intervention}

375 patients (270 with PDVT or pulmonary embolism, or both, and 105 with CDVT) were allocated to short term (3 mo for PDVT-pulmonary embolism, $6 \mathrm{wk}$ for CDVT) oral anticoagulant treatment, and 361 patients (269 with PDVT or pulmonary embolism, or both, and 92 with CDVT) were allocated to long term (6 mo for PDVT-pulmonary embolism, 12 wk for CDVT) treatment with oral anticoagulants. Fluindione was used for oral anticoagulation with dose adjustments to maintain an international normalised ratio of 2.0 to 3.0.

\section{Main outcome measures}

Incidence of recurrent venous thromboembolism and haemorrhage (major, minor, or fatal).

\section{Main result}

Intention to treat analyses showed that the treatment groups did not differ for incidence rates of recurrent venous thromboembolism and haemorrhage (table).

\section{Conclusions}

In patients with proximal deep venous thrombosis or pulmonary embolism, or both, 6 months is equivalent to 3 months of treatment with anticoagulants for preventing recurrences and bleeding complications. Similarly, in patients with calf deep venous thrombosis, 6 weeks is equivalent to 12 weeks of treatment with oral anticoagulants.

*See glossary.

\section{COMMENTARY}

5 previous, well-designed, randomised trials have compared different durations of anticoagulation for venous thromboembolism (VTE) ${ }^{1-5} 3$ of these studies tested whether the duration of anticoagulation could be reduced from $3^{13}$ or 6 months ${ }^{2}$ to only 4 or 6 weeks in patients who, for the most part, had a first episode of VTE and did not have cancer. All 3 studies found that shortening the duration of treatment resulted in about a 2-fold increase in the rate of recurrent VTE after anticoagulants were stopped, without being associated with a convincing reduction in the rate of bleeding. These studies also found that the risk for recurrent VTE was about 4 times higher for "unprovoked" or "idiopathic" VTE than for thrombosis that was provoked by a transient risk factor, such as recent surgery.

The other 2 trials evaluated an extended duration of anticoagulant treatment in 2 groups of patients with VTE who were thought to have a high risk for recurrence: those with a second episode of $\mathrm{VTE}^{4}$ and those with a first unprovoked episode of VTE. ${ }^{5}$ Both studies found that extending oral anticoagulant treatment (international normalised ratio of 2.0 to 3.0) was effective for preventing recurrent VTE; however, long term use was associated with a substantial risk for bleeding. Schulman $e t a l^{4}$ concluded that after a second episode of thrombosis the risk for recurrent VTE after completing 6 months of treatment (about 6\% per year) was not high enough to routinely recommend extended treatment. Our group found that after a first episode of unprovoked thrombosis, the risk for recurrent VTE after completing 3 months of treatment was higher than expected (about 25\% during the first year), which justified treatment for longer than 3 months; however, we could not say how much longer than 3 months was required. ${ }^{5}$ 


\section{3 months and 1 year of oral anticoagulant treatment were equivalent for idiopathic proximal deep venous thrombosis}

Agnelli G, Prandoni P, Santamaria MG, et al, and the Warfarin Optimal Duration Italian Trial Investigators. Three months versus one year of oral anticoagulant therapy for idiopathic deep venous thrombosis. N Engl J Med 2001 Jul 19;345:165-9.

QUESTION: In patients who have had a first episode of idiopathic proximal deep venous thrombosis, what is the long term effectiveness of extending to 1 year the initial 3 month course of oral anticoagulant treatment?

\section{Design}

Randomised (unclear allocation concealment*), unblinded, ${ }^{*}$ controlled trial with $\geqslant 2$ years of follow up.

\section{Setting}

10 study centres in Italy.

\section{Patients}

267 patients (mean age 67 y, 58\% men) who had a first episode of symptomatic idiopathic proximal deep venous thrombosis confirmed by compression ultrasonography or venography, and had completed 3 uninterrupted months of oral anticoagulant treatment without a recurrence of thromboembolism or bleeding. Exclusion criteria included anticoagulant treatment for reasons other than venous thromboembolism, major psychiatric disorders, life expectancy $<2$ years, and inability to return for follow up. $90 \%$ of patients completed the study.

\section{Intervention}

After 3 months of treatment with warfarin $(97 \%$ of patients) or acenocoumarol, 133 patients were allocated to discontinue (3 mo treatment group) and 133 patients to continue (1 y treatment group) oral anticoagulant treatment for 9 additional months. The dose of the oral anticoagulant was adjusted to maintain an international normalised ratio of 2.0 to 3.0 .

\section{Main outcome measures}

The primary outcome was recurrent deep venous thrombosis. Secondary outcomes were major bleeding and all-cause mortality.

\section{Main results}

At $\geqslant 2$ years, intention to treat analyses showed that the groups did not differ for incidence rates of recurrent deep venous thrombosis, major bleeding, and all-cause mortality (table). The study had an $80 \%$ power to detect a $50 \%$ reduction in the risk of recurrence at the $5 \%$ level of significance.

\section{Conclusion}

In patients who had a first episode of idiopathic proximal deep venous thrombosis, 3 months was equivalent to 1 year of oral anticoagulant treatment in preventing recurrences at $\geqslant 2$ years.

*See glossary.

1 year $v 3$ months'treatment with oral anticoagulants for proximal deep venous thrombosis

\begin{tabular}{lcccl}
$\begin{array}{l}\text { Outcomes at } \geqslant 2 \\
\text { years }\end{array}$ & $\begin{array}{l}1 \text { year } \\
\text { treatment }\end{array}$ & $\begin{array}{c}3 \text { months' } \\
\text { treatment }\end{array}$ & RRR $(95 \%$ Cl) & NNT \\
\hline Recurrence & $16 \%$ & $16 \%$ & $1 \%(-72$ to 43$)$ & Not significant \\
\hline All-cause mortality & $5 \%$ & $5 \%$ & $1 \%(-165$ to 63$)$ & Not significant \\
\hline & & & RRI $(\mathrm{Cl})$ & NNH \\
\hline Major bleeding & $3 \%$ & $2 \%$ & $99 \%(-57$ to 817$)$ & Not significant \\
\hline
\end{tabular}

†Abbreviations defined in glossary; RRR, RRI, NNT, NNH, and Cl calculated from data in article.
Source of funding: not stated.

For correspondence: Professor G Agnelli, Sezione de Medicina Interna e

Cardiovascolare, Dipartimento di Medicina Interna Università di Perugia, Via Enrico dal Pozzo, 06123 Perugia, Italy.

\section{COMMENTARY_continued from previous page}

In a mix of patients with provoked and unprovoked VTE, Pinede $e t$ al found the risk for recurrent VTE to be similar after completing 3 and 6 months of treatment. In patients with a first episode of unprovoked deep venous thrombosis, Agnelli $e$ al found a similar risk for recurrent VTE after completing 3 months and 12 months of treatment. In the latter study, this risk was only about 5\% per year, much lower than the 25\% observed after 3 months of treatment in a similarly defined patient population. ${ }^{5}$

A consistent finding across studies is that 3 months of anticoagulant treatment is adequate for patients with VTE that has been provoked by a major transient risk factor. The subsequent risk for recurrence is low ( $<5 \%$ per year); however, uncertainty exists when the risk for recurrence after an unprovoked VTE is as low after 3 months of treatment as it is after 6 months. Although the 2 new studies strongly suggest that 3 months of treatment achieves as low a subsequent risk for recurrent VTE as 6 or 12 months of treatment, neither study had the power to establish this definitively. On the basis (mostly) of the results of our own study, ${ }^{5}$ which is representative of our patient population, I will continue to recommend a minimum of 6 months of anticoagulant treatment for a first unprovoked episode of VTE, provided patients do not have a high risk for bleeding. Current evidence suggests that patients with unprovoked VTE who have been treated for 6 months or longer have a risk for recurrent VTE of about $10 \%$ during the year after anticoagulant treatment is stopped. Therefore, once patients have successfully completed 6 months of treatment, I encourage them to remain on long term treatment provided they have a low risk for bleeding and do not find treatment a burden.

1 Research Committee of the British Thoracic Society. Optimum duration of anticoagulation for deep-vein thrombosis and pulmonary embolism. Lancet 1992;340:873-6.

2 Schulman S, Rhedin AS, Lindmarker P, et al. A comparison of six weeks with six months of oral anticoagulant therapy after a first episode of venous thromboembolism. N Engl J Med 1995;332:1661-5.

3 Levine MN, Hirsh J, Gent M, et al. Optimal duration of oral anticoagulant therapy: a randomized trial comparing four weeks with three months of warfarin in patients with proximal deep vein thrombosis. Thromb Haemost 1995;74:606-11.

4 Schulman S, Granqvist S, Holmstrom M, et al. The duration of oral anticoagulant therapy after a second episode of venous thromboembolism. $N$ Engl J Med 1997;336:393-8.

5 Kearon C, Gent M, Hirsh J, et al. A comparison of three months of anticoagulation with extended anticoagulation for a first episode of idiopathic venous thromboembolism. N Engl J Med 1999;340:901-7. 